\title{
Varactor Diode Loaded Reconfigurable Patch Antenna with Adjustable Slots
}

\author{
Ritika Tandon \\ M.Tech Scholar, Subharti University, \\ Meerut, U.P. India.
}

\begin{abstract}
A VARACTOR diode is placed on every slot to alter the current direction, which determines the polarization state. The influences of the slots and varactor diodes on antenna performance are minimized because the slots and diodes are not on the patch. The simulated results verified the effectiveness of the proposed antenna configuration. A variation in parameters like RL, gain and radiated power is achieved.
\end{abstract}

\section{Keywords}

Reconfigurable, varactor, gain, RL.

\section{INTRODUCTION}

Reconfigurable antennas play an important role in modern wireless communication systems, such as personal communications service (PCS) and wireless local area network (WLAN). Reconfigurable antennas with polarization diversity can realize frequency reuse, which expands the capability of communication systems, and are useful when the operating frequency band is limited. Polarization diversity antennas can also alleviate the harmful influence caused by multipath effects. It is easy for a single-fed patch antenna to activate circular polarization $(\mathrm{CP})$ wave by a perturbing the path of the current on the antenna element in many ways. The common method for perturbation is by cutting or adding a small part on a square, a circular, or a triangle patch; for reconfigurability, this part can be connected to the patch through a varactor diode, which acts as a switch [1]-[5]. To activate such a diode, a dc bias circuit and an isolated area are on the same side of the patch with the via being holed from the patch to the ground. Patch antennas with controlled slots can also reach the aim of polarization reconfiguration. Different lengths of U-slot on the center of patch can excite two CP waves or one linear polarization (LP) and one CP [6]. A proximity-fed patch with cross slots can switch polarization states among two orthogonal LPs and right-hand CP (RHCP) [7]. A square ring slot with the center part being perturbed is capable of switching between left-hand CP (LHCP) and RHCP [8]. A square slot antenna fed by coplanar waveguide has wider operation bandwidth and low gain [9]. Since diodes and capacitors on patches influence the antenna's performances in some degree, to minimize their influence, perturbations were realized by slots on the ground [10]. However, eight diodes and four capacitors are required to obtain LHCP and RHCP. This design motivates our current investigation. In this letter, a novel reconfigurable patch antenna with polarization agility is suggested. The design of the antenna consists of a traditional square patch, ground plane with two square slots, and two varactor diodes. The advantages of slotted ground plane are to omit the dc area and to minimize the effect of diodes on the radiation performances of the antenna. Simulation, fabrication, and experiments are carried out, and detailed data are presented. The antenna is relatively concise, exhibits low fabrication cost, and hence is

\author{
Tejbir Singh \\ Assistant Professor, Subharti University, Meerut, \\ U.P. India.
}

suitable for the rapidly developing modern wireless communication systems.

\section{ANTENNA DESIGN}

The geometry of the proposed antenna is shown in Fig. 1. The top layer is a square patch, and the bottom one is ground plane for both RF and dc operations. Two little square patches on the ground plane are isolated out by a loop slot. Both the patch and the ground plane are made of perfectly conducting material. Ac-cording to the cavity theory, the operating frequency is deter-mined by the side length $L$ of the square patch, and a feed point with $50 \Omega$ input impedance is located on the symmetric axial of the $y$-axis and about $1 / 3 \quad L$ away from the lower edge, which is denoted as $H$. A small square loop slot in the ground is cut underneath the area of the upper left corner of the patch. The square slot with side length $w$ and slot width $s$ is located at an offset of $l$ distance from the patch side. The slot width on the right- hand side is expanded to $d$ in order to allow for the place-ment of the diode across this side of the slot.

\section{ANALYSIS AND DESIGN OF VARACTOR LOADED PATCH ANTENNA}

The VARACTOR diode equivalent circuit is an important part in simulation of reconfigurable antenna in order to get the similar results with measurement. This section elaborates on the VARACTOR diode that used in this antenna design using Computer Simulation Technology (CST) AND HFSS ver. 11.0 software. Two types of VARACTOR diode representation are simulated and discussed which are using lumped element and PEC pad.

The Value of equivalent lumped elements like RLC component for a VARACTOR diode to be in ON and OFF state is as given in the Table I.

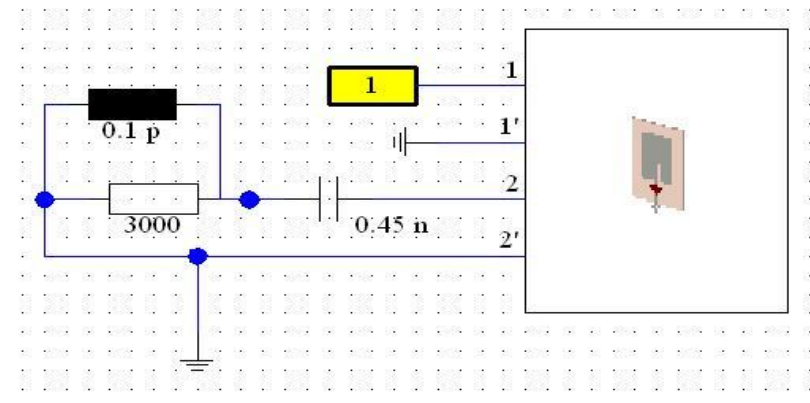

Fig 1. Schematic design of VARACTOR Diode 
Table 1. Value Of Lumped Element At Different Modes

\begin{tabular}{|c|c|c|c|}
\hline $\begin{array}{c}\text { VARACTOR } \\
\text { Diode } \\
\text { Modes }\end{array}$ & $\begin{array}{c}\text { Resistor } \\
(\Omega)\end{array}$ & $\begin{array}{c}\text { Inductor } \\
(H)\end{array}$ & Capacitor $(F)$ \\
\hline ON & 3.5 & $1.0 \times 10^{-11}$ & $0.45 \times 10^{-9}$ \\
\hline OFF & 3000 & 0 & $0.45 \times 10^{-9}$ \\
\hline
\end{tabular}

\section{RESULTS AND DISCUSSION}

The results like return loss, radiated power and gain of antenna is described in figure 4, 5 and 6.The value of return loss clearly shows that there is a shift in return loss towards left side (fig. 4), therefore antenna miniaturization is achieved. Fig. 5 shows an improvement in radiated power and fig. 6 shows a gain enhancement of $2 \mathrm{dBi}$ when the diodes are in $\mathrm{ON}$ and OFF state. Fig 1, 2 and 3 shows the basic geometry of radiating patch.
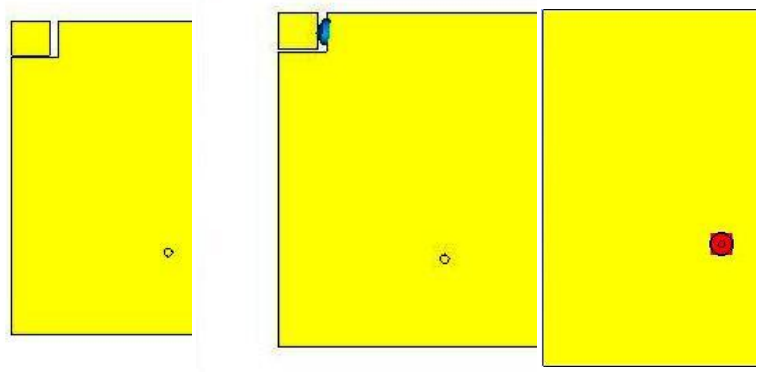

Fig 1: Patch with with no active component
Fig 2: Patch with with two diode at slot location
Fig 3:

Ground

Plane and coaxial feed location
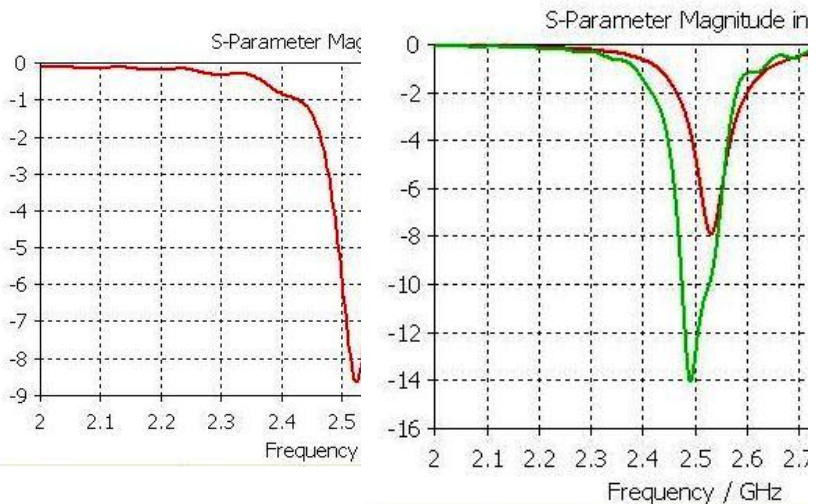

Fig 4: Return Loss Graph

(a) No component is loaded (b) Loaded wih two diodes with the slot
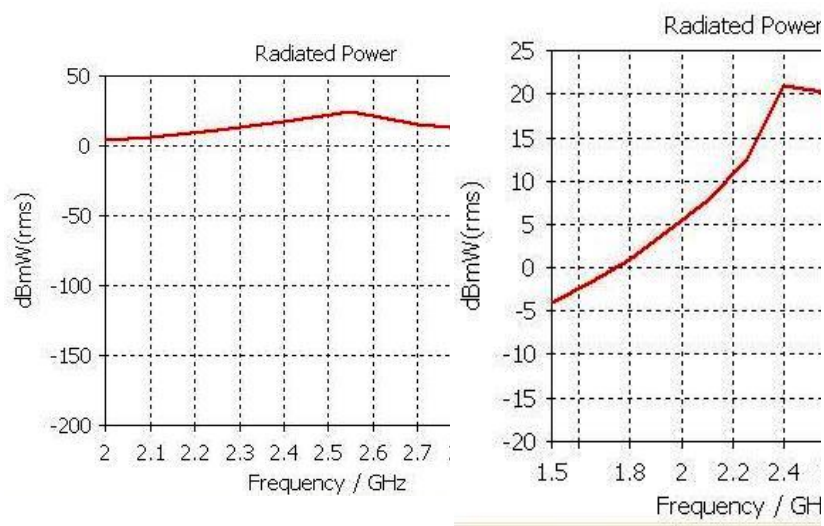

Fig 5 Radiated Power (dBmW) Vs Frequency Plot

(a) No component is loaded (b) Loaded wih two diodes with the slot
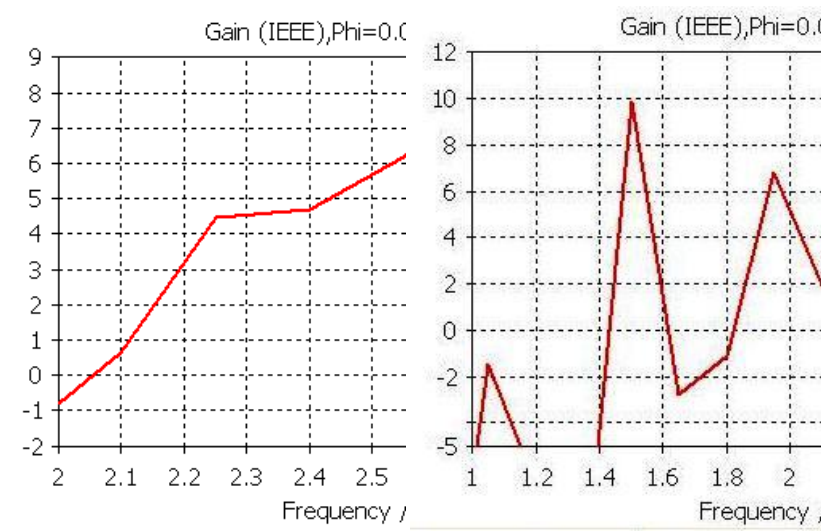

Fig 6 Gain (dBi) Vs Frequency Plot

(a) No component is loaded (b) Loaded wih two diodes with the slot

The above graphs clearly shows that the resonance frequency is shifted towards left by a value of $0.3 \mathrm{Ghz}$ (from $2.52 \mathrm{GHz}$ to $2.49 \mathrm{GHz}$ ) and antenna miniaturization is achieved when the diodes are in $\mathrm{ON}$ state.

The value of radiated power is also reported a good shift and the gain achieved the value of $2 \mathrm{dBi}$ (from $8 \mathrm{dBi}$ to $10 \mathrm{dBi}$ )

The radiation pattern, axial ratio shows the polarization of antenna. The table shows the detailed mechanism of operation of diodes integrated with antenna. There are four possible combination of diode position and their corresponding polarization is as shown in the table below. It is clearly evident from the table that one element is ON keeping the second element OFF, the polarization is either RHCP (right hand circularly polarized) or LHCP (left hand circularly polarized). While it is a LINEAR polarization when both the switch is either ON or OFF.

Table 2. Operation Of Diode Integrated With Antenna

\begin{tabular}{|c|c|c|c|}
\hline S.NO. & $\begin{array}{c}\text { ELEMENT } \\
\mathbf{1}\end{array}$ & $\begin{array}{c}\text { ELEMENT } \\
\mathbf{2}\end{array}$ & POLARISATION \\
\hline 1 & ON & OFF & RHCP \\
\hline 2 & OFF & ON & LHCP \\
\hline 3 & OFF & OFF & LINEAR \\
\hline 4 & ON & ON & LINEAR \\
\hline
\end{tabular}




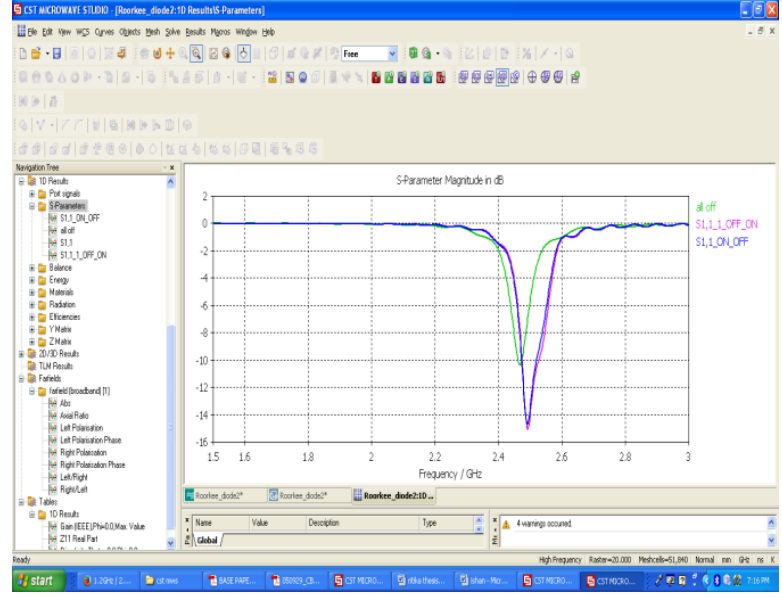

Fig 7 Return loss graph in CST environment

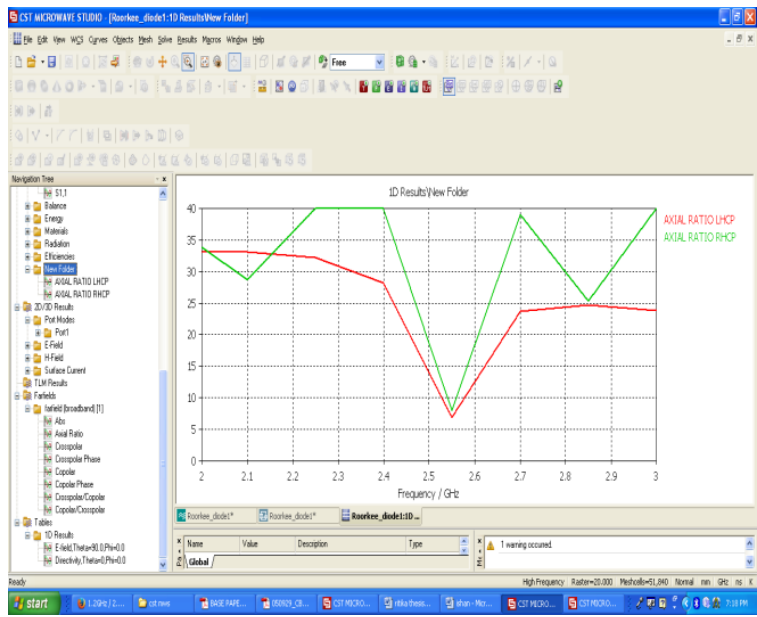

Fig 8 Axial Ratio Vs Frequency plot

\section{ON_OFF (RHCP)}

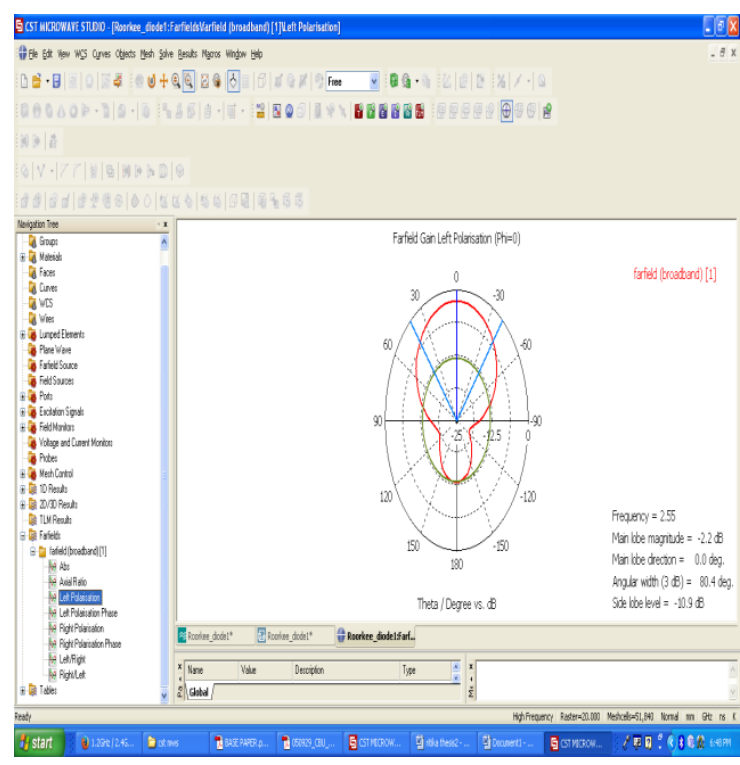

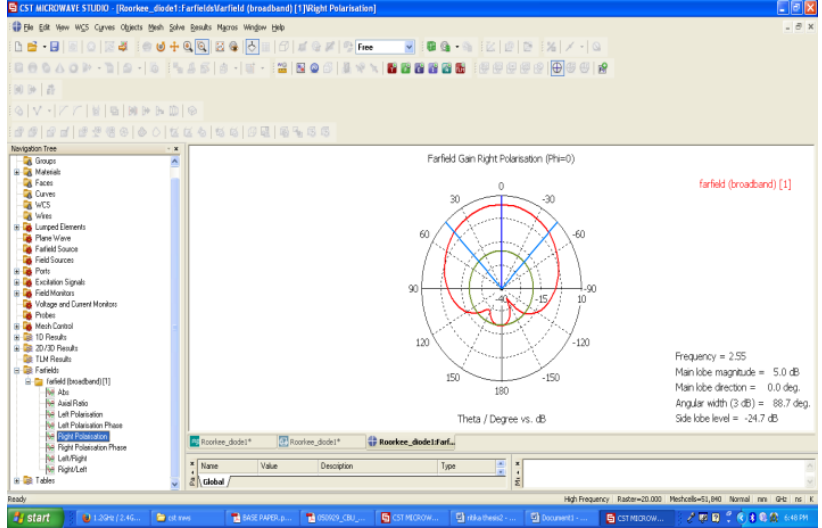

Fig 9: far field gain (element $1 \mathrm{ON}$ and element $2 \mathrm{OFF}$ state)

Figure 8 shows the LHCP operation corresponding to the switch position. It is clear that when diode 1 is ON keeping the second OFF, the value of far field gain by setting the polarization type as "axial ratio" shows the left hand circularly polarized operation. When the position of switch is reversed it shows the RHCP behavior (figure 9).
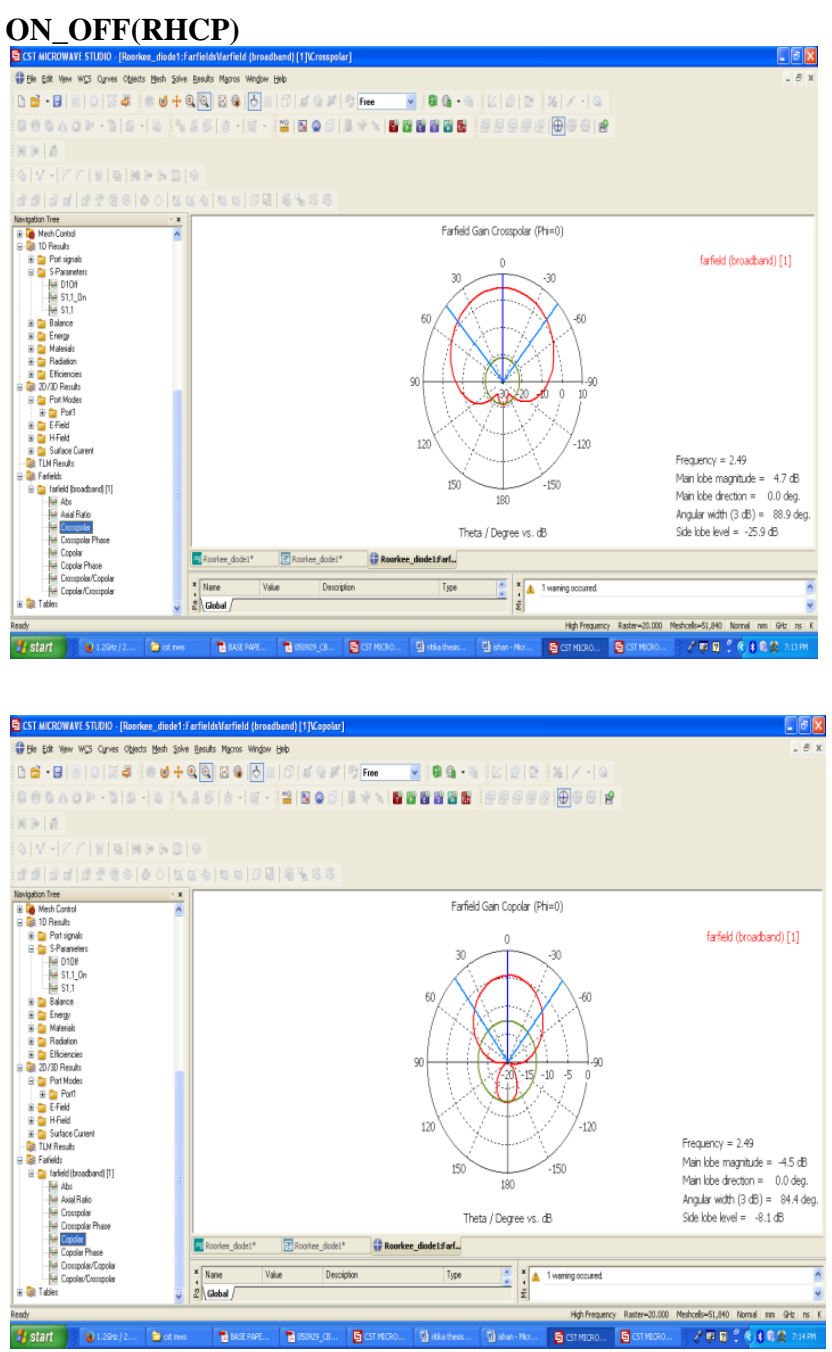

Fig 10: far field gain (element $1 \mathrm{ON}$ and element $2 \mathrm{OFF}$ state) 
The polarization is LINEAR when both switches are in the same state (either ON or OFF). The detail operation of linear polarization is as shown in the figure 10 .

\section{LINEAR (both ON or OFF)}

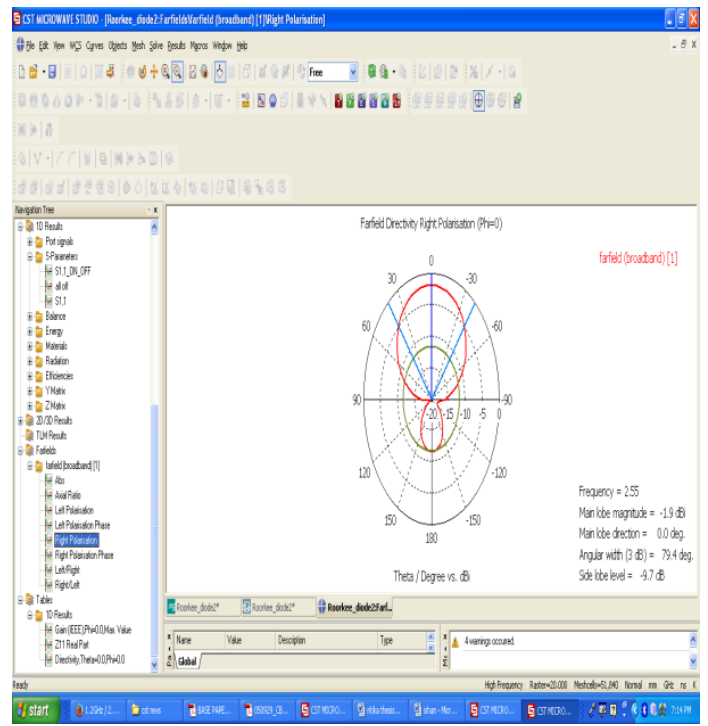

Fig 10: far field directivity (both element is either ON/OFF)

\section{CONCLUSION}

The influences of the slots and varactor diodes on antenna performance are minimized because the slots and diodes are not on the patch. The simulated results verified the effectiveness of the proposed antenna configuration. A variation in parameters like RL, gain and radiated power is achieved. The results clearly shows that the resonance frequency is shifted towards left by a value of $0.3 \mathrm{Ghz}$ (from $2.52 \mathrm{GHz}$ to $2.49 \mathrm{GHz}$ ) and antenna miniaturization is achieved when the diodes are in $\mathrm{ON}$ state. The value of radiated power is also reported a good shift and the gain achieved the value of $2 \mathrm{dBi}$ (from $8 \mathrm{dBi}$ to $10 \mathrm{dBi}$ )

\section{ACKNOWLEDGEMENT}

I express my sincere and heartfelt gratitude to my supervisor Mr. Tejbir Singh, for his invaluable suggestions and inspiring guidance and above all her limitless patience. I thank her for being instrumental in making this project a great success. At the outset I would like to express my immense gratitude to our Principal Dr. Jayant Shekhar for all the facilities provided by him for the successful completion of the project work. I am also grateful to Mr. Amit Choudhary, M. Tech. Convener for providing proper information at right time for the successful completion of this project. I would also like to thank Mr. Dharmendra Verma for reviewing the project, for his kind cooperation and valuable suggestions.

\section{REFERENCES}

[1] S. Hsu and K. Chang, "A novel reconfigurable microstrip antenna with switchable circular polarization," IEEE Antennas Wireless Propag. Lett. vol. 6, pp. 160-162, 2007.

[2] N. Jin, F. Yang, and Y. Rahmat-Samii, "A novel patch antenna with switchable slot (PASS): Dual-frequency operation with reversed cir-cular polarizations," IEEE Trans. Antennas Propag., vol. 54, no. 3, pp. 1031-1034, Mar. 2006.

[3] S.-X. Cao, X.-X. Yang, B. Gong, and B.-C. Shao, "A reconfigurable microstrip antenna with agile polarization using diode switches," in Proc. IEEE Antennas Propag. Soc. Int. Symp., 2011, pp. 1566-1569.

[4] B. Kim, B. Pan, S. Nikolaou, Y.-S. Kim, J. Papapolymerou, and M. M. Tentzeris, "A novel singlefeed circular microstrip antenna with recon-figurable polarization capability," IEEE Trans. Antennas Propag., vol. 56, no. 3, pp. 630-638, Mar. 2008.

[5] Y. Sung, "Investigation into the polarization of asymmetrical-feed tri-angular microstrip antennas and its application to reconfigurable an-tennas," IEEE Trans. Antennas Propag., vol. 58, no. 4, pp. 1039-1046, Apr. 2010.

[6] P.-Y. Qin, A. R. Weily, Y. J. Guo, and C.-H. Liang, "Polarizaion recon-figurable U-slot patch antenna," IEEE Trans. Antennas Propag., vol. 58, no. 10, pp. 33833388, Oct. 2010.

[7] M. S. Nishamol, V. P. Sarin, D. Tony, C. K. Aanandan, P. Mohanan, and K. Vasudevan, "An electronically reconfigurable microstrip an-tenna with switchable slots for polarization diversity," IEEE Trans. An-tennas Propag., vol. 59, no. 9, pp. 3424-3427, Sep. 2011.

[8] W. M. Dorsey, A. I. Zaghloul, and M. G. Parent, "Perturbed square-ring slot antenna with reconfigurable polarization," IEEE Antennas Wireless Propag. Lett., vol. 8, pp. 603-606, 2009.

[9] Y. Li, Z. Zhan, W. Chen, and Z. Feng, "Polarization reconfigurable slot antenna with a novel compact CPWto-slotline transition for WLAN Application," IEEE Antennas Wireless Propag. Lett., vol. 9, pp. 252-255, 2010.

[10] W.-S. Yoon, J.-W. Baik, H.-S. Lee, S.-M. Han, and Y.-S. Kim, "A reconfigurable circularly polarized microstrip antenna with a slotted ground plane," IEEE Antennas Wireless Propag. Lett., vol. 9, pp. 1161-1164, 2010. 